\title{
Gene therapy: The US FTC explains it all to you
}

After its recent triumphant foray into the intricacies of gene therapy, little about the US Federal Trade Commission (FTC) would be surprising. It now seems entirely possible that FTC has among its staff a panel of world authorities on the dialectical inflections of 14th-century Karelian and their relationship to the ancient Magyar languages. The FTC is admittedly better known for its role in enforcing a variety of federal antitrust and consumer protection laws, and to be sure, during working hours, FTC employees are more likely to be harmonizing US clothing care labeling regulations with those of Canada and Mexico. But who is to say that within the FTC's 6th Street offices in Washington there does not dwell a quorum of adepts in the lost arts of cabalistic synarchy?

Of late, FTC has been occupied with the Swiss multinational pharmaceutical and agribusiness companies Ciba-Geigy and Sandoz and their merger to form Novartis. FTC noted that Novartis would have an uncomfortably monopolistic position in the US market for maize herbicides: Accordingly, the company divested part of its interests to BASF. Novartis also seemed to FTC to be strong in controlling cat and dog fleas, so the company is to sell that business to Central Garden and Pet Supply. But then FTC showed its technological mettle. Surveying Novartis' intellectual property portfolio and its determined pursuit of clinical applications in gene therapy, it did not like what it saw. It wisely determined that the US gene therapy market as a whole was under threat from the merger.
In this, FTC has shown truly wondrous insight. Even though no gene therapy has proved itself effective in the clinic, FTC established that Novartis's products and processes would overcome all the technical and clinical hurdles necessary for it to reach the market (FTC did point out, of course, that this wouldn't happen much before the year 2000). Not only that, but FTC was able to foresee that Novartis products would dominate those markets when faced with competing products. Furthermore, FTC cleverly anticipated that legal challenges to Novartis' intellectual property position in gene therapy would not occur or would fail.

No one can fail to be impressed by the understanding of gene therapy that FTC has assimilated in just a few months time. From a standing start-and unlike scurrilous patent lawyers-it rapidly became able to judge what is and what is not a potentially dominant intellectual property position. It has shamed such pharmaceutical companies as Rhône Poulenc Rorer and Boehringer Ingleheim, who have misguidedly wasted huge sums of money on gene therapy investments when it must have been obvious that Ciba and Sandoz, separately or combined, would dominate completely. And it has exposed as charlatans all those analysts, company executives, and clinical researchers in gene therapy who have misled investors about the prospects for alternative, non-Novartis technologies.

FTC is to be congratulated for clarifying concisely what, to others, has so often seemed a baffling and intricate technological endeavor.

\section{Miami Winter Symposium gets back to basics}

As usual, this month's Miami Nature Biotechnology Winter Symposium features distinguished investigators whose work lies clearly in the domain of basic research sharing the podium with preeminent scientists from industry. Science to industry, industry to science: With the emergence of biotechnology companies all over the developed world, we are no longer surprised by the crossover. And with the 20-20 vision of hindsight, it is apparent that out of one is born the other.

The recipients of this year's special symposium prizes are a case in point. The Feodor Lynen prize winners are Günter Blobel (The Rockefeller University), James Rothman (Memorial Sloan-Kettering Cancer Center), and Gottfried Schatz (University of Basel), each of whom has made fundamental discoveries concerning the molecular trafficking of cells. Dr. Blobel has demonstrated the existence of the proteinconducting channel in the endoplasmic reticulum and has now turned his attention to the nuclear pore complex and the elucidation of the mechanisms of protein transport into, and out of, the nucleus. Dr. Rothman has identified the components and function of vesicle budding and fusion machinery, which has implications that go beyond yeast cell biology to the specific events of synaptic neurochemical transmission. Working on a model for common principles of protein translocation and sorting, Dr. Schatz has identified the soluble factors and the mitochondrial receptors that allow the passage of proteins across this channel.

Such achievements have earned our awardees their deserved reputations as leaders in modern cell and molecular biology. Although it is probably inadvisable to try to draw a straight line from their basic research to its implications for biotechnological development, there are connections to be made nevertheless.

For example, although the pharmaceutical significance of Ira Pastan's work (US National Institutes of Health) - this year's "Special Achievement Award" winner-on the development of recombinant single-chain antibodies for their therapeutic potential may seem obvious now, this application came out of his early studies on Pseudomonas exotoxin translocation. Similarly, Alan Fersht (University of Cambridge)-this year's "Distinguished Service" awardee-whose studies of the structure/function relationships of enzyme activity in engineered proteins paved the way for rational drug design, initially focused his research on bacterial enzymes that had no obvious biotechnological potential.

All of them share a characteristic that is endemic to both the basic and applied research communities-a desire to address a question for its own sake. To say that basic science is the engine that drives industry may by now be taken for granted. What we must continue to do is to create an environment that not only allows basic and applied research to coexist, but one in which these integral parts of the research community can maintain a scientific dialog.

Does this mean it is the job of biotechnology to fund basic research and the duty of governments to support industry? Yes, but more likely these ends will best be achieved if we can foster and value scientific inquiry for its own sake, regardless of anticipated long-term benefits. We view our annual winter symposium as a small contribution toward this goal. 